\title{
AFFECTIVE AND NEUROPSYCHOLOGICAL COGNITIVE DYSFUNCTIONS OF THE GIARDIASIS INFECTION AMONG ORPHANAGE CHILDREN IN SHARKIA GOVERNORATE
}

\author{
By \\ MAHA S. BADAWEY ${ }^{1 *}$, AND NAGY M. FAWZY ${ }^{2}$ \\ Departments of Parasitology ${ }^{1}$ and Psychiatry ${ }^{2}$, Faculty of Medicine, Zagazig \\ University, Sharkia Governorate, Egypt \\ ( ${ }^{\star}$ Correspondence: mahasaber2007@yahoo.com)
}

\section{Abstract}

This study determined the affective disorders (anxiety \& depression) and neuropsychological cognitive dysfunctions of Giardia infection among orphanage children.

The sample included 294 infected children and 200 uninfected children recruited from four orphanages in Sharkia District, Egypt. Children between 5-12 years old, both sexes without social limitation were subjected to the study. Morning stool samples were collected in labeled cartoon boxes and examined for intestinal parasites mainly Giardia lamblia. Also, all children were subjected to the cognitive dysfunction determination by using the Wisconsin card sorting test (WCST), detection of affective disorders by Hospital Anxiety and Depression Scale (HADS). The results showed lower performance in Giardia infected group than the giardiasis-free ones regarding neuropsychological tests. The infected children showed lower performance than uninfected ones on Trial A and Trail B, but higher anxiety and depression score than uninfected children.

Key words: Egypt, Orphanage children, Giardiasis, Neuro-psychological disorders.

\section{Introduction}

Diarrhea in children causes malnutrition which increase morbidity and mortality in the developing countries, and affect the cognitive development (Grantham-McGregor, 1995). Early childhood diarrhea, defined as attacks of diarrhea in the $1^{\text {st }}$ two years age, and negatively related with tests of cognitive function, verbal fluency and physical fitness growth faltering (Lorntz et al, 2006).

The hierarchical maturation of neocortical association areas, myelinisation, neuronal arborisation, emergence of brain networks and the interaction with environment are factors affecting early cognition development (Olness, 2003). Nutrition and infection have effect on neuroplasticity and development of children. Many hazards of brain developments like head injury, Iodine and iron deficiencies cause decrease in cognitive development (Guerrant et al, 1999).

The relation between diarrhea, malnutrition, education, social and economic status was difficult to determine the cause of cognition dysfunction. Childhood diarrhea disturbed visual-motor function, auditory shortterm memory information process-ing func- tioning, and cortical cognitive fu-nction (Ajjampur et al, 2011). Association between parasitosis and impaired cognitive function and educational level was reported (McGarvey and Nokes, 1999). Chronic schistosomiasis japonicum was associated with poor short-term memory and slow reactions in children whom were improvement in cognition after treatment (Jukes et al, 2002). Trichuris trichura and ascariasis (Nokes et al, 1991) and malaria infection (Al Serouri et $a l, 2000$ ) caused impaired cognitive function and decrease in educational achievement. Treatment of these nematodes increased height and muscular growth, improved heart rate recovery and increased the appetites (Stephenson et al, 1993). Giardia spp. affected about $20 \%$ to $30 \%$ of population, with reports of $100 \%$ in some areas; while $3 \%$ to $7 \%$ in developed countries (Jensen et al, 2009). Giardia and Cryptosporidium correlated with stunting, lower cognitive function scores, psycho-motor development defect and poor language cognition (Berkman et al, 2002). This was confined to either by giardiasis itself (Quihui-Cota et al, 2010) or by micronutrient deficiencies of zinc, iron and/ 
or A \& B12 vitamins deficiency (AbouShady et al, 2011). Besides, about $1 / 3$ of the giardiasis patients suffered from iridocyclitis, retinal hemorrhages and choroiditis (Barraquer, 1938), hypokalemia induced myopathy (Genove-se et al, 1996), long-term extraintestinal manifestations (Cantey et al, 2011) and loss of epithelial surface of intestine and subsequent mal-digestion, mal-absorption followed by growth retardation (Halliez et $a l, 2013)$, as well as fatigue $(41 \%)$ in outbreak in Norway (Hanevik et al, 2012)

On the other hand, the Egyptian Orphans shelter whether governmental or private is to live in a place where adaption and health advancement and social care, and institutional care is often followed continuously by the problematic psychosocial functioning of children (Al Ali 2000).

The present study aimed to evaluate the relation between giardiasis and neuropsychological cognitive dysfunctions among children in four Orphans in Sharkia Governorate.

\section{Subjects and Methods}

The study was done in the period from 16-2016 to 1-4- 2017, samples were recruited from 600 males and females. Children aged between 5-12 years old of both sexes all social and educational classes and all children lose one or both parents, the exclusive criteria were mental retardation syndromes, history of general physical diseases or psychiatric disorder.

Ethical aspect: A formed written consent was performed from the Ministry of Social Welfare Authorities in Sharkia Governorate and other written consent was attended from the caregivers or legal relatives of orphanages children, also oral awareness about the study to participant.

Data collection: The sociodemographic data, clinical and familial information were collected by the child follow-up sheet introduced to participants and their caregivers.
Parasitological examination: Three fecal samples were collected in clean wide labeled containers and examined immediately with wet mount smear and formol-ether sedimentation methods (O'Handley et al, 2000). Smears were stained in hematoxylin and eosin, Lugol's iodine solution (Xiao et al, 2014) as well as in modified Ziehl-Neelsen (ZN) staining to detect coccidian (Cheesbrough, 2004). Stools were examined macroscopically for consistency and mature or parts of worms. Stained smears were examined for worm eggs and protozoa. Duration and number of vomiting attacks per 24 hours (if present), fever during episode and/or dehydration level were recorded (Morris et al, 1994).

Wisconsin card sorting test (WCST) for determination of neuropsychological cognitive function (Schmittmann et al, 2006), which assessed the ability to abstract reasoning and to shift cognitive strategies due to environmental contingencies changing (Reitan, 1958). The WCST1 describe the total number of category completed by the subject within the 128 cards matched, while WCST2 described the subjective total perseveration errors done during matching the 128 cards (Heaton et al, 1993).

Hospital Anxiety and Depression Scale (HADS) was carried out to detect the anxiety and depression among the studied patients

Statistical analysis: Data were documented as numbers and percentages for qualitative socio-demographic variables, other correlation done by Statistical Package for the Social Sciences (SPSS) version 19.0 of the studied groups. The level of significance selected was $P$ value $<0.05$ and $<0.001$ statistically highly significant.

\section{Results}

Children with parasites other than giardiasis were excluded. The encountered cases were 294 giardiasis (patients) and 200 (control).

Details were given in tables (1, 2, 3 \& 4). 
Table 1: Sociodemographic data of infected and uninfected group

\begin{tabular}{|l|c|c|c|c|}
\hline \multirow{2}{*}{ Variable } & \multicolumn{2}{c|}{ Giardiasis children 294 } & \multicolumn{2}{c|}{ Control children 200 } \\
\cline { 2 - 5 } Male & No. & $\%$ & No. & $\%$ \\
Female & 226 & 77 & 118 & 59 \\
\hline Residence Rural & 68 & 23 & 82 & 41 \\
Urban & 89 & 30 & 69 & 35 \\
\hline Education: Received one parent & 205 & 70 & 131 & 65 \\
Ignorant & 221 & 75 & 121 & 60 \\
\hline Lost & 73 & 25 & 79 & 40 \\
Both & 244 & 16.5 & 67 & 33 \\
\hline Family communication +ve & 163 & 83.5 & 133 & 67 \\
Negative & 131 & 56 & 111 & 55 \\
\hline \multicolumn{2}{|c|}{$1.8 \pm 2.47$} & 89 & 45 \\
\hline Age at admission (yrs.) & Mean & \pm SD & Mean & \pm SD \\
\hline Orphanage residence (yrs.) & \multicolumn{2}{|c|}{$6.6 \pm 4.62$} & \multicolumn{2}{c|}{$6.2 \pm 3.76$} \\
\hline
\end{tabular}

Table 2: Comparison between infected and uninfected children as regard to executive functions

\begin{tabular}{|l|c|c|c|c|c|c|}
\hline \multirow{2}{*}{ Variable } & \multicolumn{2}{|c|}{ Giardiasis children } & \multicolumn{2}{|c|}{ Control children } & \multirow{2}{*}{$\mathrm{T}$} & \multirow{2}{*}{$\mathrm{P}$} \\
\cline { 2 - 5 } & Mean & \pm SD & Mean & \pm SD & & \\
\hline Trail A & 44.53 & 15.42 & 39.17 & 16.64 & 3.672 & 0.000 \\
\hline Trail B & 140.41 & 48.76 & 90.94 & 37.47 & 12.118 & 0.001 \\
\hline WCST 1 & 4.81 & 2.24 & 6.94 & 2.90 & 9.193 & 0.000 \\
\hline WCST 2 & 20.90 & 7.97 & 10.92 & 5.38 & 15.47 & 0.000 \\
\hline
\end{tabular}

Table 3: Comparison between infected and uninfected children as regard to memory

\begin{tabular}{|l|l|c|c|c|c|c|}
\hline \multirow{2}{*}{ Variable } & \multicolumn{2}{|c|}{ Giardiasis children } & \multicolumn{2}{c|}{ Control children } & \multirow{2}{*}{$\mathrm{T}$} & \multirow{2}{*}{$\mathrm{P}$} \\
\cline { 2 - 6 } & Mean & $\pm \mathrm{SD}$ & Mean & $\pm \mathrm{SD}$ & & \\
\hline Information & 5.10 & 1.19 & 5.21 & 1.21 & 1.001 & 0.317 \\
\hline Orientation & 3.6 & 0.71 & 3.5 & 0.5 & 1.722 & 0.086 \\
\hline Mental Control & 5.900 & 0.576 & 5.84 & 0.450 & 1.238 & 0.216 \\
\hline Logic memory & 7.985 & 2.632 & 12.610 & 0.651 & 24.342 & 0.000 \\
\hline Digit span forward & 7.06 & 1.12 & 7.33 & 1.778 & 2.008 & 0.045 \\
\hline Digit span backward & 4.889 & 0.993 & 5.12 & 1.02 & 2.5102 & 0.012 \\
\hline Associative learning & 18.38 & 1.73 & 24.40 & 1.85 & 36.908 & 0.000 \\
\hline Total memory & 73.242 & 7.415 & 76.875 & 4.749 & 6.126 & 0.000 \\
\hline
\end{tabular}

Table 4: comparison between hospital anxiety and depression scale (HADS) score among groups

\begin{tabular}{|c|c|c|c|}
\hline Parameter & Giardiasis children & Control children & $\mathrm{P}$ \\
\hline HADS & $9.3 \pm 2.5$ & $7.4 \pm 1.9$ & 0.001 \\
\hline
\end{tabular}

\section{Discussion}

Generally speaking, Giardia lamblia (syn. G. duodenalis and G. intestinalis) is one of the most frequent enteroparasites worldwide and has been included in the WHO as neglected disease initiative particularly among children (Savioli et al, 2006). G. lamblia infection can occur through ingestion of dormant cysts in contaminated water or food, or by the fecal-oral route (through poor hygiene practices). The cyst can survive for weeks to months in cold water (Huang and White, 2006). So, it can be present in the contaminated wells and water systems, especially stagnant water sources, such as naturally occurring ponds, storm water storage systems and clean-looking mountain streams in rural areas (Daniels et al, 2015) and even in commercial fresh juices in urban areas (Mossallam, 2010). Besides, Giardia relies on glucose as its major energy source and breaks glucose down into ethanol, acetate and carbon dioxide. However, it can also use arginine as an energy source (Brown et al, 1998)

In Egypt, giardiasis is a wide-spread intestinal disease of both humans and animals; without any morphological distinction between different assemblages and/or genotypes (Amer, 2013). Morsy et al. (1991) in Qualyobia Governorate reported that ecto and endoparasites were still one of the pub- 
lic health problems among primary school students. They added that these children were exposed to the intestinal parasitic infections (amoebiasis, ascariasis, enterobiasis, giardiasis, hymenolepiasis, taeniasis and schistosomiasis) or infestations (pediculosis and scabiasis). Makhlouf et al. (1994) in Cairo among children living in two orphanages; Ain-Shams and El-Mowassa reported amoebiasis, cryptosporidiosis, enterobiasis, giard-iasis, hymenolepiasis). They reported that children in institutions as orphanages were more exposed to intestinal parasites, since cro-wding and behavioral pattern contribute greatly to the spread of infections. Morsy et al. (2000) an orphanage children in Nasr City reported pediculosis $(59 \%)$ and scabies $(26.9 \%)$, transmitted by contagious, especially among children in crowded areas. Mahmud et al. (2001) in Bilbeis reported $G$. lamblia infection in lactating children, as asymptomatic infections as long as four months, with a mean duration of excretion of 7.18 weeks. They added that breast-fed infants had fewer clinical manifestations, including mucus in stool, loss of appetite, and abdominal tenderness compared with infants who were not exclusively breast-fed. They concluded that breast-feeding must be considered as an effective means to prevent giardiasis and should be encouraged in highly endemic regions.

Eldash et al. (2013) in Al-Fayoum University's hospitals stated that recurrent abdominal pain (RAP) affected 10-20\% of school-aged children. Helicobacter pylori and Giardia intestinalis were among organic causes of RAP, with different prevalence particularly in the developing countries as the common association diseases causing agents. They evaluated the incidence of $H$. pylori and $G$. intestinalis co-infection in RAP Egyptian among 90 children and 90 cross matched healthy controls. Giardiasis was found in $47(52.2 \%)$ patients and 30 $(33.3 \%)$ controls with a significant difference.

Helmy et al. (2014) in Ismailia G. reported that the prevalence of giardiasis was $53 \%$ in ruminants \& $21 \%$ in symptomatic children without positively correlated with diarrheal symptoms, as typing analysis proved predominance of B-type sequences $(>67 \%)$ in humans, and E-type sequences $(>81 \%)$ in ruminants over A-type sequences. They concluded that the risk of zoonotic giardiasis infection emanated from ruminants even in high prevalence areas was negligible. Genetic characterization indicated a predominant anthropogenic infection cycle within the pediatric population studied. Integration of sequence typing data with information on geographic origins of samples allowed parasite sub-population tracing using current typing tools. Fahmy et al. (2015) in Cairo stated that the genetic of giardiasis studies proved that at least eight assemblages (A-H) exist. Only, A \& B were found primarily in man and occasionally in animals. The association between clinical symptoms and giardiasis assemblages was controversial. They concluded that giardiasis infection with assemblage $\mathrm{B}$ was more common than that with assemblage A. No associations between epidemiological information and assemblage were detected, except with age. Although infections with assemblage $\mathrm{B}$ were more frequently associated with abdominal pain and acute diarrhea than with assemblage A, the difference was not statistically significant. Genotyping of $G$. duodenalis isolated from various hosts has shown that assemblages $\mathrm{A}$ and $\mathrm{B}$ infect the largest range of host species, and appear to be the main (or possibly only) G. duodenalis assemblages that undeniably infect human subjects (Heyworth, 2016)

On the other hand, the persistent diarrhea was followed by decreased nutritional status, but early childhood diarrhea and nutritional level were independently correlated with impaired cognitive function (Kaur et al, 2002). There were a high number of mental health problems, predominantly those of emotional nature. The early childhood malnutrition like micronutrient deficiency (Ka- 
pil and Bhavna 2002), anemia and helminthiases (Seshadri and Gopaldas 1989) were reported to affect cognitive development. In other countries as Brazil (Patrick et al, 2005), Malaysia, (Al-Mekhlafi et al, 2005), Turkey (Celiksoz et al, 2005) and Bangladesh (Tarleton et al, 2006) reported that early childhood diarrhea usually caused by enteric protozoan. Also, the malaria infection (Berkman et al, 2002), Entamoeba histolytica (Tarleton et al, 2006) and giardiasis caused adverse effects on the academic achievement, cognitive function and physical fitness. (Celiksoz et al, 2005).

Hürlimann et al. (2014) studied the effect of deworming against soil-transmitted helminthiasis on children's physical fitness, cognition and clinical parameters in a malaria-helminth co-endemic setting of Côte d'Ivoire. They found that treatment had no effect on haemoglobin levels and anemia, but children with moderate- to heavy-intensity parasitic infection at the baseline gained weight more pronouncedly than non-infected children. They speculated that potential beneficial effects of deworming were likely to be undermined in areas where malaria was coendemic and nutritional deficiencies were widespread.

The present study showed marked impairment in the neuropsychological cognitive function in giardiasis patients in which the cognitive domains showed lower performance than controls on Trail A and Trail $\mathrm{B}$, as well as WCST with high significant difference as to their functions and attention,

In the pilot study, children showed a prolonged impact of early childhood diarrhea on the visual-motor coordination, auditory short-term memory information processing, and cortical cognitive function. Conversely, the forward digit span correlated with activity scores, and prospective problem solved in correlated with nutritional status, but not with diarrhea rates (Guerrant et al, 1999). Also, Partovi et al. (2007) who detected that giardiasis children were affected cognitive functions compared to controls regarding affected short term memory and long-term memo-ry while that of arithmetic and coding test showed no significant difference between them. Weissman et al. (1999) showed that cognitive abnormalities were mild, transitory Zubieta et al. (2001) reported that infected children group had confirmed existence of cognitive deficits. This difference might in the small size, which did not demonstrate a significant relation between early childhood diarrhea and poorer fitness and cognitive function.

The present study showed greater impairment in verbal memory among patients with giardiasis. Conversely, Feldman (2009) did not find a statistical difference in logical memory between euthymic giardiasis patients and healthy control, but; they found that performance on tests of associative learning was poorer in giardiasis patients relative to controls, which was in consistence with our study. While, decrease in cognitive domains especially verbal memory and some executive functions were documented in infected children (Quraishi and Frangou, 2002).

The present study showed marked memory deficit that differed from Potter et al. (2010) who studied school children, rather than orphanage cultures that affect cognition due to social isolation and learning disabilities. But, the present data agreed with Seshadri and Gopaldas (1989) and Lorntz et al. (2006).

In the present study, the prevalence rate of depression and anxiety in orphan patients was higher than controls. But, the total anxiety depression rates were somewhat lower than those in other countries. The sympathy, social support and the advices in holly Quran to look after the orphan child, helped to decrease psychiatric disorder and socioculture burden among orphans (Fawzy and Fouad, 2010). The present results went with study performed on children admitted to orphanages in Gaza Strip where (39.3\%) suffered from post-traumatic stress disorder were considered as an evidence of anxiety, Thus, orphaned children were affected by 
both exposure to trauma and family loss due to occupation and/or wars. The low psychosocial support made them vulnerable to depression (Thabet et al, 2007). The present results agreed with Jorngarden et al. (2006) where the patients scored significantly worse than the controls for both anxiety and depression based on the HADS scores. Frequencies of depression and anxiety among patients according to this score did not represent primary form, but reflected comorbid illness secondary to long-standing chronic fatigue. Sharpe et al. (1992), Moss-Morris and Spence (2006) and Afari and Buchwald (2003) reported similar or higher HADS scores among patients with chronic fatigue, orph- ans unsatisfied about their circumstances with emotional problems associated with high risk of adult mentality.

\section{Conclusion}

Orphan or institution children demonstrated high rates of psychiatric symptoms. Institutionalization duration, physical stature, and age at abandonment differentially relate to psychiatric symptoms. Findings are interpreted in light of implications for intervention and social policy.

The outcome results showed a high rate of cognitive dysfunctions and affective disorders strongly correlated with giardiasis prevalence among orphanages children. Undoubtedly, the schoolaged children are the group at risk group for ecto- and endo-parasites conveying these parasites, particularly those transmitted by contagious and autoinfection to other colleagues and their family members.

\section{Recommendations}

Critically, the governmental authorities must establish official system to address the orphan's problems in the community and enhancing social support services.

\section{References}

Abou-Shady, O, El Raziky, MS, Zaki, MM, Mohamed, RK, 2011: Impact of Giardia lamblia on growth, serum levels of zinc, copper, and iron in Egyptian children. Biol. Trace Elem. Res. 140, 1:1-6.
Afari, N, Buchwald, D, 2003: Chronic fatigue syndrome: a review. Am. J. Psychiat. 160, 2: 221-36

Ajjampur, SSR, Koshy, B, Venkataramani, M, Sarkar, R, Joseph, AA, J et al, 2011: Effect of cryptosporidial and giardial diarrhea on social maturity, intelligence and physical growth in children in a semi-urban slum in south India. Ann. Trop. Paediatr. 31:20-12

Al Ali, NS, 2000:.Secularism, gender and the state in the Middle East: The Egyptian women's movement. Cambridge University Press

Al-Mekhlafi, MS, Azlin, M, Nor-Aini, U, et al, 2005: Giardiasis as a predictor of childhood malnutrition in Orang Asli children in Malaysia. Trans. R. Soc. Trop. Med. Hyg. 99:686-91.

Al Serouri, AW, Grantham-McGregor, S M, Greenwood, B, Costell, A, 2000: Impact of asymptomatic malaria parasitaemia on cognitive function and school achievement of schoolchildren in the Yemen Republic. Parasitology 121:337-45.

Amer, SE, 2013: Genotypic and phylogenetic characterization of Giardia intestinalis from human and dairy cattle in Kafr El Sheikh, Egypt, J. Egypt. Soc. Parasitol. 43, 1:133-46.

Barraquer, I, 1938: Sur la coïncidence de la lambliase et de certaineslésions $\mathrm{du}$ fond de l'oeil. Bull. Soc. Pathol. Exot. 31:55-58.

Berkman, DS, Lescano, AG, Gilman, RH, Lopez, SL, Black, MM, 2002: Effects of stunting, diarrheal disease, and parasitic infection during infancy on cognition in late childhood: a follow-up study. Lancet 359:564-71

Brown, DM, Upcroft, JA, Edwards, MR, Upcroft, P, 1998: Anaerobic bacterial metabolism in the ancient eukaryote Giardia duodenalis. Inter. J. Parasitol. 28, 1:149-64.

Cantey, PT, Roy, S, Lee, B, Cronquist, A, Smith, K, et al, 2011: Study of non-outbreak giardiasis: novel findings and implications for research. Am. J. Med. 124: 1175.e1-1175.e8

Celiksoz, A, Acioz, M, Degerli, S, Cinar, Z, Elaldi, N, et al, 2005: Effects of giardiasis on school success, weight and height indices of primary school children in Turkey. Pediatr. Int. 47:567-71

Cheesbrough, M, 2004: District Laboratory Practice in Tropical Countries. $2^{\text {nd }}$ edition. Cambridge: Cambridge University Press.

Daniels, ME, Shrivastava, A, Smith, WA, Sahu, P, Odagiri, M, et al, 2015: Cryptosporidium and Giardia in humans, domestic animals, and 
village water sources in rural India. Am. J. Trop. Med. Hyg. 93, 3:596-600

Eldash, HH, Bekhit, O, Algameel, A, 2013: Impact of Helicobacter pylori-giardiasis coinfection on children with recurrent abdominal pain. J. Egypt. Soc. Parasitol. 43, 2:509-16.

Fahmy, HM, El-Serougi, AO, El Deeb, HK, Hussein, HM, Abou-Seri, HM, et al, 2015: Giardia duodenalis assemblages in Egyptian children with diarrhea. Eur. J. Clin. Microbiol. Infect. Dis. 34, 8:1573-81

Fawzy, N, Fouad, A, 2010: Psychosocial and developmental status of orphanage children: Epidemiological study. Curr. Psychiat. 17, 2:41-8

Feldman, DE, 2009: Synaptic mechanisms for plasticity in neocortex. Ann. Rev. Neurosci. 32:33-55.

Genovese, A, Spadaro, G, Santoro, L, Gasparo Rippa, P, Onorati, AM, et al, 1996: Giardiasis as a cause of hypokalemic myopathy in congenital immunodeficiency. Int. J. Clin. Lab. Res. 26:132-5

Grantham-McGregor, S, 1995: A review of studies of the effect of severe malnutrition on mental development. J. Nutr. 125:S22-38.

Guerrant, DI, Moore, SR, Lima, AA, Patrick, PD, Schorling, JB, et al, 1999: Association of early childhood diarrhea and cryptosporidiosis with impaired physical fitness and cognitive function four-seven years later in a poor urban community in northeast Brazil. Am. J. Trop. Med. Hyg. 61:707-13

Halliez, MCM, Buret, AG, 2013: Extraintestinal and long term consequences of Giardia duodenalis infections. World J. Gastroenterol. 19, 47:8974-85.

Hanevik, K, Kristoffersen, EK, Sørnes, S, Mørch, K, Næss, H, et al, 2012: Immuno-phenotyping in post-giardiasis functional gastrointestinal disease and chronic fatigue syndrome. BMC Infect. Dis. 12:25-8.

Heaton, RK, Chelune, GJ, Talley, JL, Kay, G G, Curtis, G, Eds., 1993: Wisconsin card sorting test manual: Revised and expanded. Odessa, FL: Psychological Assessment Resources.

Helmy, YA, Klotz, C, Wilking, H, Krücken, J, Nöckler, K, et al, 2014: Epidemiology of Giardia duodenalis infection in ruminant livestock and children in the Ismailia province of Egypt: insights by genetic characterization. Parasit Vect. 7:321. doi: 10.1186/1756-3305.

Heyworth, FM, 2016: Giardia duodenalis gen- etic assemblages and hosts. Parasite 23:13. doi:10. 1051/parasite/2016013

Huang, DB, White, AC, 2006: An updated review on Cryptosporidium and Giardia. Gastroenterol. Clin. North Am. 35, 2:29-314,

Hürlimann, E, Houngbedji, CA, N'Dri, PB, Bänninger, D, Coulibaly, JT, et al, 2014: Effect of deworming on school-aged children's physical fitness, cognition and clinical parameters in a malaria-helminth co-endemic area of Côte d'Ivoire. BMC Infect. Dis. Jul 25;14:411. doi: 10.1186/1471-2334-14-411.

Jensen, LA, Marlin, JW, Dyck, DD, Laub ach, HE, 2009: Prevalence of multi-gastrointestinal infections with helminth, protozoan and Campylobacter spp. in Guatemalan Children. J. Infect. Dev. Ctries. 3:229-34.

Jorngarden, A, Wettergen, L, von Essen, L, 2006: Measuring health-related quality of life in adolescents and young adults: Swedish normative data for the SF-36 and HADS, and influence of age, gender, and method of administration. Hlth. Qual. Life Outcomes 4:91

Jukes, MC, Nokes, CA, Alcock, KJ, Lambo, JK, Kihamia, C, et al, 2002: Heavy schistosomiasis associated with poor short- term memory and slower reaction times in Tanzanian schoolchildren. Trop. Med. Hlth. 7:104-17.

Kapil, U, Bhavna, A, 2002: Adverse effects of poor micronutrient status during childhood and adolescence. Nutr. Rev. 60:S84-90.

Kaur, R, Rawat, D, Kakkar, M, Uppal, B, Sharma, VK, 2002: Intestinal parasites in children with diarrhea in Delhi, India. Southeast Asian J. Trop. Med. Publ. Hlth. 33:725-9.

Lorntz, B, Soares, AM, Moore, SR, et al, 2006: Early childhood diarrhea predicts impaired school performance. Pediatr. Infect. Dis. J. 25:513-20

Mahmud, MA, Chappell, CL, Hossain, MM, Huang, DB, Habib, M, et al, 2001: Impact of breast-feeding on Giardia lamblia infections in Bilbeis, Egypt. Am. J. Trop. Med. Hyg. 65, 3:257-60

Makhlouf, SA, Sarwat, MA, Mahmoud, DM, Mohamad, AA, 1994: Parasitic infection among children living in two orphanages in Cairo. J. Egypt. Soc. Parasitol. 24, 1:137-45.

McGarvey, S, Nokes, LS, 1999: Schistosoma japonicum and cognition in children from Sichan, China. Am. J. Hum. Biol. 81:123.

Morris, SS, Cousens, SN, Lanata, CF, Kirk 
wood, BR, 1994: Diarrhea-defining the episode. Int. J. Epidemiol. 23:617-23.

Morsy, TA, Farrag, AM, Sabry, AH, Salama, MM, Arafa, MA, 1991: Ecto and endoparasites in two primary schools in Qualyob City, Egypt. J. Egypt. Soc. Parasitol. 21, 2: 391-401. Morsy, TA, el-Ela, RG, Morsy, AT, Nassar, MM, Khalaf, SA, 2000: Two contagious ectoparasites in an orphanage children in Nasr City, Cairo. J. Egypt. Soc. Parasitol. 30, 3: 727-34. Mossallam, SF, 2010: Detection of some intestinal protozoa in commercial fresh juices. J. Egypt. Soc. Parasitol. 40, 1:135-49

Moss-Morris, R, Spence, M, 2006: To "lump" or to "split" the functional somatic syndromes: can infectious and emotional risk factors differentiate between the onset of chronic fatigue syndrome and irritable bowel syndrome? Psychosom. Med. 68, 3:463-9.

Nokes, C, Cooper, ES, Robinson, BA, Bundy, DA, 1991: Geo-helminthic infection and academic assessment in Jamaican children. Trans. R. Soc. Trop. Med. Hyg. 85:272-4.

Olness, K, 2003: Effects on brain development leading to cognitive impairment: a worldwide epidemic. J. Dev. Behav. Pediatr. 24:120-30

O'Handley, RM, Olso, ME, Fraser, D, et al, 2000: Prevalence and genotypic characterization of Giardia in dairy calves from Western Australia and western Canada. Vet. Parasitol. 90:193200.

Partovi, F, Khalili, G, Kariminia, A, Mahmoudzadeh-Niknam, H, 2007: Effect of $G i$ ardia lamblia infection on the cognitive function of school children. Iran. J. Publ. Hlth. 36, 1:738.

Patrick, PD, Oria, RB, Madhavan, V, et al, 2005: Limitations in verbal fluency following heavy burdens of early childhood diarrhea in Brazilian shantytown children. Child. Neuropsychol. 11:233-44.

Potter, MC, Elmer, GI, Bergeron, R, Albuquerque, EX, Wu, HQ, et al, 2010: Reduction of endogenous kynurenic acid formation enhances extracellular glutamate, hippocampal plasticity, and cognitive behavior. Neuropsychopharmacology 35:1734-42.

Quihui-Cota, L, Méndez Estrada, RO, Astiazarán-García, H, Morales-Figueroa, GG, Moreno-Reyes, MJ, et al, 2012: Changes in serum zinc levels associated with giardiasis and dietary zinc intake in mice. Biol. Trace Elem. Res. 145:396-402.
Quraishi, S, Frangou, S, 2002: Neuropsychology of bipolar disorder: a review. J. Affect. Disord. 72:209-26

Reitan, RM, 1958: Validity of the trail making test as an indicator of organic brain damage; Percept. Mot. Skills. 8:271-6.

Savioli, L, Smith, H, Thompson, A, 2006: $\mathrm{Gi}^{-}$ ardia and Cryptosporidium join the 'Neglected Diseases Initiative' Trends Parasitol. 22, 5:2038.

Schmittmann, VD, Visser, I, Raijmakers, ME, 2006: Multiple learning modes in the development of performance on a rule-based categorylearning task. Neuropsychologia 44, 11:2079-91. Seshadri, S, Gopaldas, T, 1989: Impact of ir-on supplementation on cognitive functions in preschool and school-aged children: the Indian experience. Am. J. Clin. Nutr. 50:675-86.

Sharpe, M, Hawton, K, Seagroatt, V, Pasvol, G, 1992: Follow up of patients presenting with fatigue to an infectious diseases clinic. Brit Med. J. 305, 6846:147-52

Stephenson, LS, Latham, MC, Adams, EJ, Kinoti, SN, Pertet, A, 1993: Physical fitness, growth and appetite of Kenyan school boys with hookworm, Trichuris trichiura and Ascaris lumbricoides infections are improved four months after a single dose of albendazole. J. Nutr. 123:1036-46.

Tarleton, JL, Haque, R, Mondal, D, Shu, J, Farr, BM, et al, 2006: Cognitive effects of diarrhea, malnutrition, and Entamoeba histolytica infection on school age children in Dhaka, Bangladesh. Am. J. Trop. Med. Hyg. 74:475-81.

Thabet, L, Mousa, TAA, Abdul Hussein, S, Vostanis, P, 2007: Mental health problems among orphanage children in the Gaza Strip. Adopt. Foster. J. 31, 2:54-62

Weissman, MM, Wolk, S, Goldstein, RB, Moreau, D, Adams, P, Green et al, 1999: Depressed adolescents grown up. JAMA 281, 18: 1707-13.

Zubieta, JK, Huguelet, P, O'Neil, RL, Giordani, BJ, 2001: Cognitive function in bipolar I disorder. Psychiat. Res. 102:9-20.

Xiao, T, Kurita, H, Li, X, Qi, F, Shimane, T, et al, 2014: Iodine penetration and glycogen distribution in vital staining of oral mucosa with iodine solution. Oral Surg. Oral Med. Oral Pathol. Oral Radiol. 117, 6:754-9. 